\title{
Binding of titanium dioxide nanoparticles to lactate dehydrogenase
}

\author{
Mazen S. K. Zaqout • Tomoyuki Sumizawa • \\ Hideki Igisu • Donald Wilson • \\ Toshihiko Myojo $\cdot$ Susumu Ueno
}

Received: 30 June 2011 / Accepted: 21 September 2011/Published online: 13 October 2011

(C) The Japanese Society for Hygiene 2011

\begin{abstract}
Objective Measurement of released lactate dehydrogenase (LDH) activity, a commonly used marker of lethal cell injury in both in vitro and in vivo screenings, has been used to assess the cytotoxicity of nanoparticles (NPs), chemical compounds, and environmental factors. We have recently demonstrated that titanium dioxide $\left(\mathrm{TiO}_{2}\right)$ particles bind to several serum proteins. In the present study we investigated the binding of $\mathrm{TiO}_{2}$ NPs to $\mathrm{LDH}$.

Methods Purified LDH was incubated with $\mathrm{TiO}_{2} \mathrm{NPs}$ at $37^{\circ} \mathrm{C}$ for $1 \mathrm{~h}$. The particles were then sedimented by centrifugation, and the activity and quantity of LDH in the supernatant and precipitated fraction were analyzed.

Results Incubation with $\mathrm{TiO}_{2}$ reduced the $\mathrm{LDH}$ activity in the supernatant in a dose-dependent manner, while LDH activity in the precipitated fraction increased in a dosedependent manner. Moreover, sodium dodecyl sulfate-
\end{abstract}

M. S. K. Zaqout · D. Wilson · S. Ueno $(\bowtie)$

Department of Occupational Toxicology, Institute of Industrial

Ecological Sciences, University of Occupational and

Environmental Health, Yahatanishi-ku,

Kitakyushu 807-8555, Japan

e-mail: susumu@med.uoeh-u.ac.jp

T. Sumizawa

Department of Domestic Science, Kagoshima Women's Junior

College, Korai-cho, Kagoshima 890-8565, Japan

H. Igisu

Fukuoka Central Health Evaluation and Promotion Center,

Chuo-ku, Fukuoka 810-0054, Japan

\section{T. Myojo}

Department of Environmental Health Engineering, Institute of Industrial Ecological Sciences,

University of Occupational and Environmental Health,

Yahatanishi-ku, Kitakyushu 807-8555, Japan polyacrylamide gel electrophoresis analysis revealed a $\mathrm{TiO}_{2}$ dose-dependent reduction in the quantity of LDH protein in the supernatant and an increase of LDH in particulate re-suspensions.

Conclusions These findings, although based on a purified form of $\mathrm{LDH}$, suggest that $\mathrm{TiO}_{2}$ NPs bind to $\mathrm{LDH}$, and consequently, $\mathrm{TiO}_{2}$ NP-induced toxicity could be underestimated by the LDH activity assay.

Keywords Titanium dioxide $\cdot$ Nanoparticle . Lactate dehydrogenase $\cdot$ Cytotoxicity $\cdot$ Protein binding

\section{Introduction}

Lactate dehydrogenase (LDH) is an enzyme that exists in the soluble cytoplasmic fraction of cells. In cells that are damaged and in which the integrity of their membranes is lost, LDH leaks from the cells. Therefore, the activity of released LDH is a common diagnostic test for the cytotoxicity induced by chemicals in vitro, and it is also used as an indicator of cellular and tissue damage from such causes as hemolysis, myocardial infarction, cancer, meningitis, and encephalitis [1,2].

Titanium dioxide $\left(\mathrm{TiO}_{2}\right)$, a fine, white pigment, is used commercially in a wide range of products including paints, cosmetics, foods, and pharmaceuticals, and has been employed as a photocatalyst to clean air and industrial waste water [3]. Due to the extensive use of $\mathrm{TiO}_{2}$ and the fact that nano-sized particles are generally more toxic than their larger-sized counterparts [4], concern for the potential risk of $\mathrm{TiO}_{2}$ nanoparticles (NPs) to humans has increased. Measurement of LDH activity in culture media (in vitro studies) [5] and in blood and bronchoalveolar lavage fluid (in vivo studies) [6] has been utilized in numerous studies 
to assess the cytotoxic effects of metal oxide NPs, including those of $\mathrm{TiO}_{2}$.

We have observed that with A549 cells (human pulmonary epithelial type II cells) exposed to $\mathrm{TiO}_{2} \mathrm{NPs}$ for $24 \mathrm{~h}, \mathrm{LDH}$ activity in the cell culture medium dropped markedly at higher $\mathrm{TiO}_{2}$ concentrations, even though there was a $\mathrm{TiO}_{2}$ dose-dependent decrease in cell viability as determined by the 3-[4,5-dimethylthiazol-2-yl]-2,5-diphenyltetrazolium bromide (MTT) assay (unpublished data). Based on our recent data showing that $\mathrm{TiO}_{2}$ particles bind to several serum proteins [7], we hypothesized that $\mathrm{TiO}_{2}$ NPs could bind to the LDH protein, which might account for the observed effect of $\mathrm{TiO}_{2} \mathrm{NPs}$ on measured LDH activity, particularly if centrifugation is a step in the assay protocol. To provide insight into this possibility, purified LDH preparations were mixed with $\mathrm{TiO}_{2} \mathrm{NPs}$, followed by centrifugation to separate the supernatant from the precipitated $\mathrm{TiO}_{2}$ NPs, and the activity and amount of LDH protein in the supernatant was determined. The supernatant LDH activity was also analyzed with respect to the crystal structures of these NPs.

\section{Materials and methods}

\section{Materials}

Anatase $\mathrm{TiO}_{2}$ (primary size $<25 \mathrm{~nm}, 99.7 \%$ ) and rutile $\mathrm{TiO}_{2}$ (primary size $<100 \mathrm{~nm}, 99.5 \%$ ) were purchased from Sigma-Aldrich (St. Louis, MO, USA). Amorphous $\mathrm{TiO}_{2}$ (primary size $<50 \mathrm{~nm}, 99.9 \%$ ) was purchased from Wako Pure Chemicals (Osaka). L-Lactate dehydrogenase (L-LDH) from rabbit muscle suspension $(5 \mathrm{mg} / \mathrm{ml}$ suspension in $3.2 \mathrm{M}$ ammonium sulfate solution, $\mathrm{pH} 7$ ), and a Cytotoxicity Detection Kit (LDH) were purchased from Roche Diagnostics (Mannheim, Germany). Ready Gel (10-20\% linear gradient) for sodium dodecyl sulfatepolyacrylamide gel electrophoresis (SDS-PAGE), Bio-Safe Coomassie Brilliant Blue (CBB) G-250 stain, and Precision Plus protein standard were purchased from Bio-Rad Laboratories(Hercules, CA, USA). Dulbecco's modified Eagle medium (DMEM) was purchased from Invitrogen (Carlsbad, CA, USA). All other chemicals were analytical grade.

\section{Reaction of LDH protein with $\mathrm{TiO}_{2}$ NPs}

The reaction mixture $(1 \mathrm{ml})$ containing $62.5 \mu \mathrm{g} / \mathrm{ml}$ of purified LDH preparation and $\mathrm{TiO}_{2}$ NPs in DMEM was incubated at $37^{\circ} \mathrm{C}$ for $60 \mathrm{~min}$ with gentle rotation. The concentrations of $\mathrm{TiO}_{2}$ particles tested here were based on the studies by Sayes et al. [8] and our group [7]. After incubation the mixture was centrifuged at $1,000 \times g$ for $15 \mathrm{~min}$ for particle sedimentation. The supernatant was collected, and the precipitated particles were washed (re-suspended and re-centrifuged) twice with either DMEM or phosphate-buffered saline (PBS). The resulting particulates were re-suspended with $1 \mathrm{ml}$ of DMEM or PBS.

LDH activity measurement

A Cytotoxicity Detection Kit (LDH) was used to measure LDH activity. The supernatants and particulate re-suspensions were incubated with the $\mathrm{LDH}$ reaction mixture for 5 min. After centrifugation to remove the particles, the supernatants were transferred to a 96-well microplate, in triplicate. Absorbance was measured at $490 \mathrm{~nm}$ with a BioRad 680 microplate reader (Bio-Rad Laboratories).

SDS-PAGE and densitometric analysis

The supernatants and particulate re-suspensions were heated at $100^{\circ} \mathrm{C}$ for $5 \mathrm{~min}$ in the presence of $1 \% \mathrm{SDS}$. After removal of particles by centrifugation, samples were loaded onto gels. Following electrophoresis, the gels were stained with $\mathrm{CBB}$, and band intensities were quantified with a CoolSaver AE-6955 using CS analyzer Ver. 2.0 (ATTO, Tokyo, Japan).

Statistical analyses

Construction of bar graphs and statistical analyses were carried out using GraphPad Prism 5 (GraphPad Software, San Diego, CA, USA). Results are expressed as means \pm SD. All experiments were carried out at least three times. Statistical significance was evaluated by analysis of variance (ANOVA) followed by Dunnett's test. $P<0.05$ was considered statistically significant.

\section{Results}

The LDH activity was observed to lessen in a $\mathrm{TiO}_{2}$ dosedependent manner, and this loss of activity was more pronounced for anatase and amorphous NPs than for rutile NPs (Fig. 1). Conversely, the LDH activity in re-suspensions of anatase and amorphous precipitated NPs was found to increase in a $\mathrm{TiO}_{2}$ dose-dependent, statistically significant manner. For rutile NPs, only re-suspensions containing the maximum $\mathrm{TiO}_{2}$ concentration $(6 \mathrm{mg} / \mathrm{ml})$ showed significant LDH activity, although at a lower level than was observed for the anatase and amorphous forms.

The amount of LDH protein remaining in the supernatant was analyzed by SDS-PAGE (Fig. 2a), and densitometric analysis was used to semi-quantify protein band intensities (Fig. 2b). Incubation with anatase and amorphous particles led to $\mathrm{TiO}_{2}$ dose-dependent decrease in the amount of LDH 

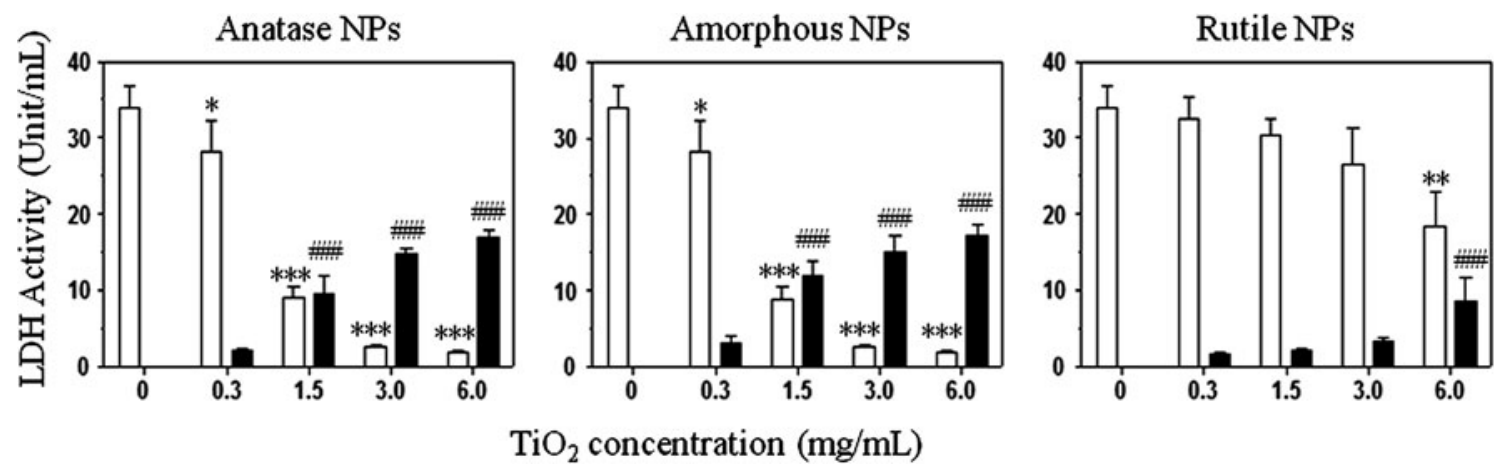

Fig. 1 Lactate dehydrogenase $(L D H)$ activity in the supernatant and $\mathrm{TiO}_{2}$ nanoparticle $(N P)$ re-suspension. The indicated concentrations of $\mathrm{TiO}_{2}$ NPs were incubated with $62.5 \mu \mathrm{g} / \mathrm{ml}$ of LDH in DMEM at $37^{\circ} \mathrm{C}$ for $1 \mathrm{~h}$. After separation of the supernatant and $\mathrm{TiO}_{2} \mathrm{NPs}$ by centrifugation at $1,000 \times g$ for $15 \mathrm{~min}$, sedimented particles were washed twice and re-suspended in DMEM. LDH activity in the supernatant and particulate re-suspension was measured and data are expressed as means $\pm \mathrm{SD}$. White and black bars represent the LDH activity in the supernatant and particulate re-suspensions, respectively. $* P<0.05$, $* * P<0.01$, and $* * * P<0.001$, using analysis of variance (ANOVA) followed by Dunnett's test, compared with the activity in the supernatant in the absence of $\mathrm{TiO}_{2} \mathrm{NPs}$ (zero $\mathrm{TiO}_{2}$ ). ${ }^{\# \# \# P} P<0.001$ using ANOVA followed by Dunnett's test, compared with the value of zero

A
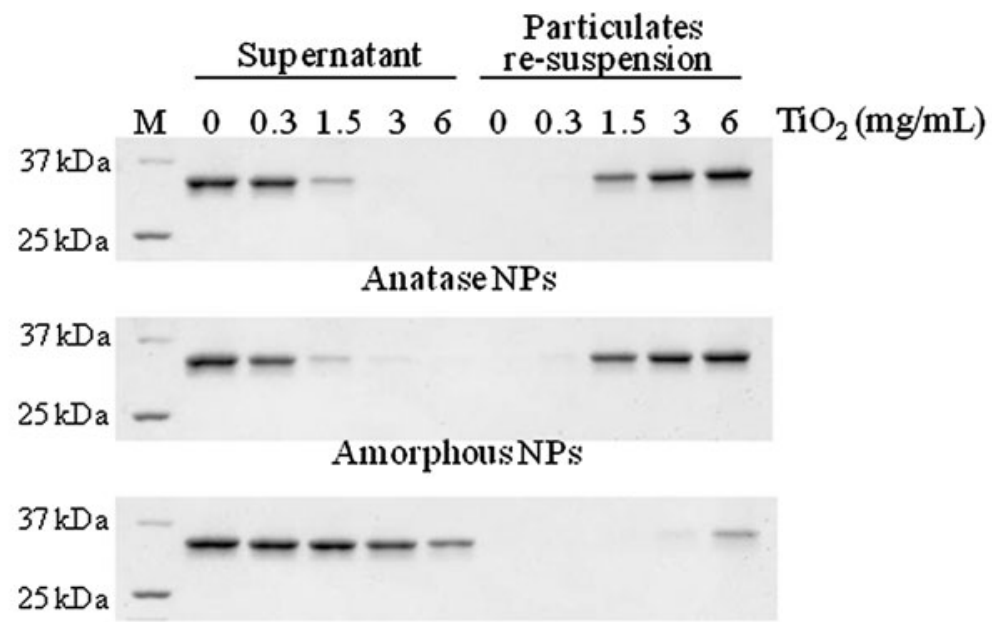

RutileNPs
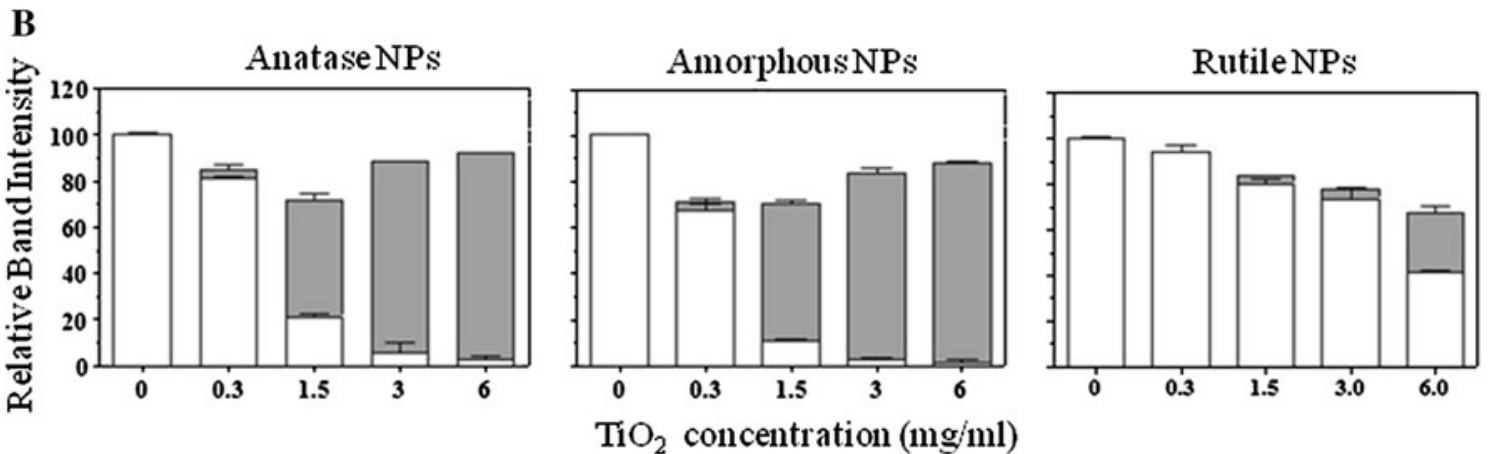

Fig. 2 Analysis of LDH protein quantity in the supernatant and $\mathrm{TiO}_{2}$ NP re-suspension by sodium dodecyl sulfate-polyacrylamide gel electrophoresis (SDS-PAGE) (a), and densitometric analysis of protein bands (b). a $\mathrm{LDH}(62.5 \mu \mathrm{g} / \mathrm{ml})$ was incubated with $\mathrm{TiO}_{2}$ NPs in DMEM at $37^{\circ} \mathrm{C}$ for $1 \mathrm{~h}$. After separation of the supernatant from $\mathrm{TiO}_{2} \mathrm{NPs}$ by centrifugation at $1,000 \times g$ for $15 \mathrm{~min}$, sedimented particles were washed twice and re-suspended in $1 \mathrm{ml}$ of PBS. The supernatant and the particulate re-suspension were then heated at $100^{\circ} \mathrm{C}$ for $5 \mathrm{~min}$ in the presence of $1 \%$ SDS. After removal of the particles by centrifugation, samples were loaded onto gels. Following electrophoresis, the gels were stained with Coomassie Brilliant Blue (CBB). $M$ represents the molecular weight marker. b LDH band intensity shown in a was quantified by densitometric analysis and was normalized to the intensity obtained from the supernatant in the absence of $\mathrm{TiO}_{2}$ NPs (zero $\mathrm{TiO}_{2}$ ). The open and gray columns represent the $\mathrm{LDH}$ band intensity from the supernatant and the $\mathrm{TiO}_{2}$ particle re-suspension, respectively. Data were obtained from three independent experiments and are presented as means \pm SD 
protein in the supernatant, which was significantly less than the amount of LDH retained in the rutile supernatant. The particulates were re-suspended in DMEM, and the suspensions were boiled in the presence of $1 \%$ SDS, which allowed LDH protein to be recovered from amorphous NPs, but not from anatase NPs (data not shown). Based on the previous finding that $\mathrm{TiO}_{2}$ particles have a high affinity for phosphate ions in aqueous solutions [9], PBS was used for particulate re-suspensions instead of DMEM. A significant amount of LDH was recovered from the re-suspensions of anatase and amorphous $\mathrm{TiO}_{2} \mathrm{NPs}$, and the LDH protein amounts were observed to increase in a $\mathrm{TiO}_{2}$ dose-dependent manner. The degree of LDH protein reduction in the supernatant after contact with NPs was consistent with the assayed LDH activity, as shown in Fig. 1.

\section{Discussion}

The measurement of LDH release from cells is a wellaccepted method for analyzing cell membrane integrity and quantifying cell cytotoxicity [10], and has commonly been used to assess the cytotoxic effect of NPs in both in vitro and in vivo screenings $[4,5]$. In clinical applications, the measurement of LDH activity as an indicator of tissue damage normally requires the use of human serum [1], a blood fraction that is acquired by centrifugation of whole blood. Centrifugation is therefore a vital step in the simple separation of blood components, as well as for in vitro and in vivo screenings of the cytotoxic effects of NPs. In the present study, we found a $\mathrm{TiO}_{2}$ dose-dependent decrease of LDH activity in the supernatants, whereas we observed a $\mathrm{TiO}_{2}$ dose-dependent increase in LDH activity from the particulate matter derived from $\mathrm{TiO}_{2} \mathrm{NPs}$. The degree of reduced activity differed by NP crystal form; incubation with anatase and amorphous NPs produced supernatants with less LDH activity than did incubation with rutile NPs. The amount of LDH protein in the supernatants also decreased in a $\mathrm{TiO}_{2}$ dose-dependent manner, and using PBS to re-suspend precipitated NPs resulted in the successful recovery of LDH protein in the aqueous fraction. These results strongly suggest that $\mathrm{TiO}_{2} \mathrm{NPs}$ bind to LDH, especially the anatase and amorphous forms. This finding also raises the possibility of underestimation of the cytotoxicity caused by these particles, particularly when centrifugation is a step in the LDH activity assay. The LDH protein could not be completely recovered from the precipitated NPs, which may have been due in part to loss of LDH protein during the washing of the precipitated fraction before it was loaded onto gels.

The use of DMEM for the re-suspension of particles allowed release of the $\mathrm{LDH}$ protein from amorphous $\mathrm{TiO}_{2}$ particles, but not from anatase $\mathrm{TiO}_{2}$ particles, even though the particles were treated with $1 \%$ SDS and were boiled for 5 min. In contrast, when PBS was used to re-suspend anatase NPs, LDH protein was almost fully recovered. Similar to these results, we have reported that the application of PBS for re-suspension significantly increased the release of serum proteins bound to $\mathrm{TiO}_{2}$ particles, but Trisbuffered saline, which does not contain phosphate ions, did not allow recovery of these proteins [7]. In addition, Connor and McQuillan [9] have reported that $\mathrm{TiO}_{2}$ particles have a higher affinity for phosphate ions in aqueous solutions. Taking these findings into consideration with the fact that the phosphate concentration is ten times higher in PBS $(10 \mathrm{mM})$ than in DMEM $(0.9 \mathrm{mM})$ suggests that a higher concentration of phosphate ions may facilitate the release of $\mathrm{LDH}$ protein from $\mathrm{TiO}_{2} \mathrm{NPs}$, possibly due to the high affinity of such particles for phosphate ions. Interestingly, with DMEM, LDH protein was released from amorphous and rutile NPs, suggesting that there could be a difference in the type of protein-particle complex formation between the LDH protein and amorphous/rutile or anatase NPs.

Our results describing lower amounts of LDH protein binding to rutile $\mathrm{TiO}_{2}$ particles, compared with anatase/ amorphous particles, seem to be consistent with our recent finding that the $\mathrm{TiO}_{2}$ particle crystal form greatly affects binding to serum proteins [7]. In that study, we measured the specific surface area (SSA) of the $\mathrm{TiO}_{2}$ particles based on the BET theory [11], but no obvious correlation was observed between the BET SSA and the binding potency of $\mathrm{TiO}_{2}$ particles to serum proteins. However, to investigate the difference in LDH protein binding between anatase/ amorphous and rutile forms, the BET SSA of the rutile particles was measured, because that of anatase and amorphous particles had been reported earlier [7]. The SSA was determined from $\mathrm{N}_{2}$ adsorption onto the sample powders, using NOVA-1200 (Quantachrome Instruments, Boynton Beach, FL, USA) in the UBE Scientific Analysis Laboratory (Ube, Japan). Surprisingly, the SSA of the rutile form $\left(2.8 \mathrm{mg}^{2} / \mathrm{g}\right)$ was much smaller than that of the anatase and amorphous forms (116 and $110 \mathrm{mg}^{2} / \mathrm{g}$, respectively). This SSA value of rutile particles does not seem correct for an NP, although this $\mathrm{TiO}_{2}$ particle is supposed to be nano-sized, according to the information provided by the manufacturer. At this point, therefore, we cannot rule out the possibility that the difference in LDH protein binding between the anatase/amorphous and rutile forms may be partly dependent on the SSA value of $\mathrm{TiO}_{2}$ particles, unlike the case of serum protein binding to $\mathrm{TiO}_{2}$ particles. Additional experiments are in progress in our laboratory to clarify this interaction.

The LDH activity from re-suspensions of NPs appeared to be lower than was expected from the amount of LDH protein bound to NPs, suggesting a possible direct 
inhibition of LDH activity due to NP binding. Because we did not measure the specific activity of LDH released from NPs, further investigation will be necessary to clarify whether NP binding has a direct inhibitory effect on LDH activity, and if so, whether the effect is reversible.

In summary, we have found that $\mathrm{TiO}_{2} \mathrm{NPs}$ bind to the LDH protein. Therefore, when enzymatic activity is utilized as a measure of cytotoxicity, it should be noted that the binding of the enzymatic proteins to $\mathrm{TiO}_{2} \mathrm{NPs}$ may cause an underestimation of $\mathrm{TiO}_{2}$ toxicity.

Acknowledgments This work was supported in part by a UOEH grant for advanced research.

Conflict of interest The authors declare no conflict of interests.

\section{References}

1. Chapman JF, Christenson RH, Silverman LM. Cardiac and muscle disease. In: Kaplan LA, Pesce AJ, editors. Clinical chemistry: theory, analysis, and correlation. St. Louis: Mosby; 1996. p. 593-612.

2. Christenson RH, Panigrahi K, Chapman JF, Silverman LM. Isoenzymes and isoforms. In: Kaplan LA, Pesce AJ, editors. Clinical chemistry: theory, analysis, and correlation. St. Louis: Mosby; 1996. p. $1077-85$.
3. Aitken RJ, Chaudhry MQ, Boxall ABA, Hull M. Manufacture and use of nanomaterials: current status in the UK and global trends. Occup Med. 2006;56:300-6.

4. Lam CW, James JT, McCluskey R, Hunter RL. Pulmonary toxicity of single wall carbon nanotubes in mice 7 and 90 days after intratracheal instillation. Toxicol Sci. 2004;77:126-34.

5. Stone V, Johnston H, Schins RP. Development of in vitro systems for nanotoxicology: methodological considerations. Crit Rev Toxicol. 2009;39:613-26.

6. Sayes CM, Reed KL, Warheit DB. Assessing toxicity of fine and nanoparticles: comparing in vitro measurements to in vivo pulmonary toxicity profiles. Toxicol Sci. 2007;97:163-80.

7. Zaqout MS, Sumizawa T, Igisu H, Higashi T, Myojo T. Binding of human serum proteins to titanium dioxide particles in vitro. J Occup Health. 2011;53:75-83.

8. Sayes CM, Wahi R, Kurian PA, Liu Y, West JL, Kevin D, et al. Correlating nanoscale titania structure with toxicity: a cytotoxicity and inflammatory response study with human dermal fibroblasts and human lung epithelial cells. Toxicol Sci. 2006; $1: 174-85$.

9. Connor PA, McQuillan AJ. Phosphate adsorption onto $\mathrm{TiO}_{2}$ from aqueous solutions: an in situ internal reflection infrared spectroscopic study. Langmuir. 1999;15:2916-21.

10. Legrand C, Bour JM, Jacob C, Capiaumont J, Martial A, Marc A, et al. Lactate dehydrogenase (LDH) activity of the number of dead cells in the medium of cultured eukaryotic cells as marker. J Biotechnol. 1992;25:231-43.

11. Brunauer S, Emmett PH, Teller E. Adsorption of gases in multimolecular layers. J Am Chem Soc. 1938;60:309-19. 